\title{
A EFICIÊNCIA DOS PROCESSOS DE INOVAÇÃO NA INDÚSTRIA DE TRANSFORMAÇÃO: UMA ANÁLISE NO ESTADO DO PARANÁ
}

\author{
Diandra Carla Uncini Brunhera \\ Mestranda em Gestão e Desenvolvimento Regional da Universidade Estadual do Oeste do Paraná - \\ UNIOESTE \\ diandra_brunhera@hotmail.com (Brasil)
}

\section{Fernanda Mendes Bezerra Baço}

Doutora em Economia pela Universidade Federal de Pernambuco - UFPE

Professora da Universidade Estadual do Oeste do Paraná - UNIOESTE

ferpompeia@gmail.com (Brasil)

\section{Poliana Cristina Crotti}

Mestranda em Gestão e Desenvolvimento Regional da Universidade Estadual do Oeste do Paraná UNIOESTE

poli_crotti@hotmail.com (Brasil)

\section{RESUMO}

Em 2011 a indústria representou 27,28\% do PIB no Estado do Paraná, representando em 2013, 5,84\% do PIB do Brasil, com destaque para os segmentos de veículos automotores, alimentos e refino de petróleo. No entanto vem-se observando nos últimos anos, um decréscimo da participação da indústria na economia, um possível processo de desindustrialização, onde verifica-se que os desafios relacionados a globalização e a maior competitividade estão diretamente ligados aos processos de inovação. O objetivo do trabalho é verificadas atividades que implementaram inovações na indústria de transformação, quais são mais eficientes em relação ao seu retorno financeiro no Estado do Paraná. A pesquisa é do tipo descritiva, onde aplica-se a técnica de programação linear análise envoltória de dados (DEA - Data Envelopment Analysis) a partir da série de dados coletados para os anos de 2000, 2003, 2005, 2008 e 2011. Utilizou-se o modelo BCC com orientação a outputs. Neste cenário, verificase que as atividades que mais inovam não possuem necessariamente as receitas líquidas mais altas, devido a questão de padrão de cada setor, relacionado a necessidade de investimentos mais altos em pesquisa e desenvolvimento de produtos com valores agregados elevados. Os resultados indicam que mesmo as indústrias com menor porte ao estimularem as atividades inovadoras, tornam-se benchmarks, aproveitando ao máximo seus recursos a fim de maximizar suas receitas, tornando o setor rentável e competitivo.

Palavras-chave: Efiência; Indústria; Inovação. 


\section{INTRODUÇÃO}

De acordo com estimativas do Fundo Monetário Internacional - FMI (2014), o Brasil tende a manter-se a sétima maior economia do mundo. O PIB do Brasil, em 2013 foi de R 4,84 trilhões conforme dados do Instituto Brasileiro de Geografia e Estatística- IBGE (2014). Deste total, a participação do setor de indústria de transformação ${ }^{1}$ representou $13 \%$, gerando em torno de $17,2 \%$ dos empregos formais na economia brasileira.

Conforme dados divulgados na Pesquisa Industrial Anual - PIA do IBGE em 2011 a indústria de transformação brasileira apresentou um valor adicionado de $\mathrm{R} \$ 515,4$ bilhões, no qual os setores com maior representação neste valor são: produtos alimentícios (14,9\%); coque, derivados do petróleo e bicombustíveis (12,4\%); e veículos automotores, carrocerias e autopeças (11,8\%).

No Estado do Paraná, em 2011, a indústria representou 27,28\% do PIB, onde os segmentos de veículos automotores, alimentos e refino de petróleo representaram aproximadamente $58 \%$ do valor da transformação industrial do Paraná. Em 2013, o PIB do estado representou 5,84\% do PIB do país, R\$ 287.966 bilhões.

O valor adicionado no Estado do Paraná, conforme dados do Instituto Paranaense de Desenvolvimento Econômico e Social (IPARDES, 2014) em 2011 era composto pelo comércio e serviços com $64,05 \%$, pela indústria com $27,28 \%$ e pela agropecuária com $8,68 \%$. A indústria de transformação paranaense representava naquele ano $7 \%$ do valor adicionado da indústria de transformação do Brasil.

Ainda conforme dados do IPARDES (2014), os segmentos de veículos automotores, alimentos e refino de petróleo/produção de álcool representam 20,9\%,19,6\% 17,4\%, respectivamente, do valor da transformação industrial do Paraná que atingiu em 2011 R \$ 67,4 bilhões, enquanto máquinas e equipamentos representaram $4,1 \%$, papel e celulose $4,2 \%$ e produtos químicos $4,4 \%$ deste total.

Brum (2000) contextualiza que a decolagem do processo de industrialização no Brasil teve a influência da Primeira Guerra Mundial, da crise do café e a da Revolução de 1930 para fomentar a iniciativa do governo em apoiar esse processo. No início a indústria nascente destinava-se apenas a demanda interna com a produção de bens de consumo imediato, uma vez que o país não possuía condições para competir com o exterior.

${ }^{1}$ Segundo IBGE (2007), indústria de transformação pode ser compreendida como as atividades que transformam química, física ou biologicamente materiais, substâncias e componentes com o objetivo de se obter produtos novos.

Revista de Administração e Inovação, São Paulo, v. 12, n.4 p. 187-204, out./dez. 2015. 
Mas a partir da Segunda Guerra Mundial, a agenda mudou e trouxe a tona a importância em atender e manter a demanda e a economia em funcionamento e o governo passou a intensificar a busca por recursos externos a fim de dinamizar a indústria com a produção de bens de consumo duráveis. No entanto, a indústria de bens de capital e insumos apenas tornou-se efetiva, implantada e expandida, a partir de 1974, mas prejudicada pela crise de 1980, que acabou defasando a capacidade produtiva do país.

De acordo com estudo apresentado pelo Departamento de Pesquisa e Estudos EconômicosFederação e Centro de Indústrias do Estado de São Paulo (DEPECONFIESP, 2014) a participação do setor industrial no Brasil cai e volta ao nível do anos do presidente JK. A partir de 1947, apresentam a expansão da participação da indústria de transformação na composição do PIB do país no governo JK, antes representava apenas $11,3 \%$, e durante o governo "cinco anos em cinco" passou a representar 19,2\%. Observa-se também uma leve queda nesse percentual para 18,30\% nos anos que ligeiramente antecederam o golpe de 1964, que em seu período de existência contribuiu de forma significativa para a ascensão da participação do setor industrial no valor do PIB, tendo como auge $27,20 \%$. Nota-se também que a partir de então, na chamada década perdida, houve uma redução atingindo $21,2 \%$, entretanto a partir da abertura econômica na era Collor verifica-se uma recuperação do setor porém tende novamente a declinar recuperando-se modestamente nos primeiro anos do governo Lula mas não resistindo a tendência de declínio constante no percentual de participação do PIB do Brasil. Em 2013 o setor industrial representou apenas 13\% desse total.

Segundo Cano (2012) o processo de desindustrialização, onde a indústria perde participação tanto no valor adicionado total quanto na geração de empregos, ocorreu tanto em países desenvolvidos como em desenvolvimento, no entanto em sentidos diferentes. Nos países em estágio mais avançado de desenvolvimento, este processo aconteceu em forma de mudança estrutural e natural, associado a uma maior produtividade industrial onde trabalhadores foram transferidos para outros setores devido a qualificação da mão-de-obra elevada desse setor, enquanto no Brasil, a desindustrialização está associada a fenômenos negativos como aumento das importações e perda competitiva nas exportações.

Diante deste processo de desindustrialização, verifica-se que a inovação possui um papel essencial para a sobrevivência das empresas num cenário cada vez mais competitivo e globalizado, contribuindo para o aumento da produtividade da indústria bem como a geração de lucros, além de progresso econômico e social.

O intuito do artigo é verificar se as atividades que implementaraminovações na indústria de transformação foram os mais eficientes em termos de receita no estado do Paraná no período de 2000, 2003, 2005, 2008 e 2011.

Revista de Administração e Inovação, São Paulo, v. 12, n.4 p. 187-204, out./dez. 2015. 
Este trabalho é composto, além desta introdução por mais quatro seções. A seção 2 apresenta uma revisão de literatura, que tem o objetivo de dar sustentação à aplicação empírica. Na seção 3 é apresentada a metodologia e a descrição dos dados. Na seção seguinte são mostrados os resultados e discussões. E por fim são tecidas algumas considerações finais na última seção.

\section{REVISÃO DA LITERATURA}

Nessa seção, será apresentado um breve relato sobre os processos de inovação e na sequência serão abordados estudos sobre o tema.

\subsection{A inovação}

Do latim innovare, inovar significa renovar e introduzir novidades de qualquer natureza. No entanto a invenção apenas se transforma em inovação quando é implementada e aceita pelo mercado, a inovação resulta de uma ideia somada a implementação e aos resultados, pode ser radical ou apenas incremental (Barbieri \& Álvares, 2004).

Para Andreassi (2007), a inovação pode estar relacionada ao produto, quando introduz em sua linha de atuação um novo produto ou serviço ou mesmo aprimora um modelo já existente. A inovação também pode estar relacionada ao processo, a gestão com introdução de novidades que afetam diretamente os processos administrativos, e também pode estar atrelada ao modelo de negócios ao modificar a essência do negócio.

As empresas consideram a inovação e o desenvolvimento de tecnologias uma forma de aumentar lucros, e sendo assim, as inovações possibilitam uma maior geração de renda e o acúmulo de riquezas além de modificar a economia e a realidade social. Por meio da diferenciação, as inovações podem ser bruscas a ponto de alterar uma organização, ou apenas ser incremental, sem provocar grandes impactos, mas melhorando o produto ou os serviços já existentes. Assim como para Schumpeter ${ }^{2}$, se houver tecnologia, esta promove competitividade e progresso social. (Silva \& Mendes, 2014).

${ }^{2}$ Joseph A. Schumpeter é considerado pioneiro no estudo da Economia da Inovação, que destaca a importância de inovar tanto para o crescimento da empresa quanto para o crescimento do país. Essa seção de revisão da literatura é baseada em sua teoria.

Revista de Administração e Inovação, São Paulo, v. 12, n.4 p. 187-204, out./dez. 2015. 
A inovação é considerada a principal força motriz do progresso e da prosperidade, consequentemente, observa-se a sua aplicação no desenvolvimento de novos conhecimentos tecnológicos, novas tecnologias de processo e de novos produtos. No entanto, a despeito da maioria das pesquisas abordar a inovação como o desenvolvimento de novas tecnologias, produtos e serviços, a inovação bem-sucedida não é apenas o resultado de inovação tecnológica. Esse processo inovativo é dependente da gestão de inovação, que consiste em mudar a forma organizacional, práticas e processos de uma empresa de uma forma que é novo para a empresa ou indústria. Dessa forma, é possível alavancar a base de conhecimento tecnológico e seu desempenho em termos de inovação, produtividade e competitividade (Volberda, Van Den Bosch \& Heij, 2013).

Ainda de acordo com os autores supracitados, a globalização e o superaquecimento dos mercados emergentes estão forçando as empresas a procurar outras áreas em que a inovação seja a arma para ganhar e manter a vantagem competitiva. Isto implica uma busca não apenas para novos produtos e novas tecnologias, mas também de mudanças na natureza da gestão dentro da empresa, ou seja, gestão da inovação.

Embora inovação seja um fator necessário para o desenvolvimento econômico, o objetivo desse trabalho é avaliar o papel das inovações para a eficiência econômica da própria empresa. Assim, não abordará todos os impactos das inovações mostradas por Schumpeter. Com relação às definições de inovação, serão testadas as inovações de produtos e processos num grupo; e em outro grupo estão incluídas as inovações organizacional e de marketing.

Inovação de produto pode ser entendida como mudanças significativas nas potencialidades de produtos e serviços, ou seja, produtos totalmente novos ou mudanças significativas em produtos já existentes. Inovação de processo representa as mudanças significativas na forma de produzir ou distribuir um produto (OCDE, 2005).

A inovação organizacional pode ser compreendida como as mudanças que acontecem na empresa quando se implementa um novo método organizacional nas práticas de negócio, na organização do local de trabalho ou nas relações da empresa com o externo. Inovação de Marketing pode ser compreendida como um novo método de marketing em que as mudanças que ocorrem são significativas ou no produto ou na forma de mostrar o produto ao consumidor (OCDE, 2005).

\subsection{Estudos sobre o tema}

Dutra et al. (2005) busca analisar o impacto do SIMPLES (Sistema Integrado de Pagamento de Impostos e Contribuições das Microempresas e das Empresas de Pequeno Porte) na competitividade

Revista de Administração e Inovação, São Paulo, v. 12, n.4 p. 187-204, out./dez. 2015. 
das empresas, e no processo de inovação. Para essa finalidade utilizou-se de revisão bibliográfica, sem qualquer metodologia quantitativa, deixando uma lacuna para trabalhos futuros.

Saunila et al. (2014) analisam a relação entre a capacidade de inovação e rentabilidade da empresa, concluindo que o efeito dos determinantes da capacidade de inovação não é pequeno sobre a rentabilidade. A metodologia utilizada foi quantitativa, coletando os dados em questionários aplicados às empresas. Além do método ser diferente do empregado aqui, Saunila et al. (2014) analisam a relação entre os determinantes da capacidade de inovação com a lucratividade, enquanto o trabalho aqui proposto analisa a relação entre volume de inovação e rentabilidade

Heij et al. (2013) argumentam que onde há baixos níveis de gestão da inovação, dentre eles ajustes na gestão de práticas e processos, percebe-se que as estruturas e técnicas não estão adequadamente alinhados com novos conhecimentos tecnológicos, de forma que permita à empresa alcançar o sucesso da inovação. Enquanto atividades com níveis mais elevados de gestão da inovação mostram um melhor ajuste que pode levar a um êxito maior no quesito inovação.

Ansari et al.(2010), em um trabalho de cunho teórico, identificam elementos técnicos, culturais e políticos de ajuste (ou desajuste) entre as práticas de difusão e adoção de inovações gerenciais. O objetivo é analisar como os processos de obtenção de ajuste podem desencadear diferentes padrões de adaptação, uma vez que dependem do contexto. Os resultados encontrados sugerem que a adoção e difusão de novas práticas gerenciais requerem esforços em todas as áreas. Esse trabalho também fica no âmbito teórico, diferente do aqui proposto.

Esses trabalhos citados não esgotam os estudos a respeito da relação entre inovação e rentabilidade. Não foram encontrados nesse levantamento bibliográfico trabalhos que utilizam a metodologia DEA para essa finalidade, sendo assim, uma contribuição dessa pesquisa.

\section{METODOLOGIA}

A pesquisa desenvolvida é do tipo descritiva, seguindo o procedimento de levantamento bibliográfico. Os procedimentos metodológicos seguirão a seguinte ordem:

- $\quad$ Obtenção de dados;

- Estimar os índices de eficiência pela Análise por Envoltória de Dados - DEA (Data Envelopment Analysis) um método não-paramétrico baseado em programação linear, com o objetivo de medir o desempenho e avaliar a eficiência de unidades operacionais ou tomadoras de decisão 
(DMUs - Decision Maker Unit), buscando comparar entidades que realizam atividades semelhantes e diferenciam-se pela quantidade de recursos utilizados (inputs) e bens produzidos (outputs).

- Análise dos Resultados: As empresas buscam maior eficiência possível no processo de produção buscando maximizar seus lucros. A programação linear será utilizada para resolver um sistema de inequações que permitirá ou maximizar os resultados (orientação output) ou minimizar a utilização dos insumos (orientação input).

\subsection{Dados}

Os dados secundários foram coletados junto ao sistema do IBGE de Pesquisa Industrial de Inovação Tecnológica - PINTEC, referentes aos anos de 2000, 2003, 2005, 2008 e 2011, devido ao fato de haver disponibilidade de dados apenas para esses períodos.

As variáveis escolhidas foram:

DMU'S: setores da indústria de transformação elencados pelo IBGE, e o número de DMU'S varia a cada ano devido a disponibilidade dos dados encontrados;

Input 1: $\mathrm{N}^{\mathrm{o}}$ de empresas que inovaram - produto ou processo;

Input 2: $\mathrm{N}^{\mathrm{o}}$ de empresas que inovaram - mudanças estratégicas, organizacionais e de marketing;

Input 3: Dispêndios realizados em atividades inovativas $(\mathrm{R} \$)$ - dispêndios realizados nas atividades de Pesquisa e Desenvolvimento (P\&D), na aquisição de máquinas e equipamentos e novos conhecimentos, no treinamento do pessoal, e na implementação efetiva de produtos e processos novos ou aprimorados.

Output 1: Receita líquida de vendas (R\$).

\subsection{Método: análise envoltória dos dados}

Para Mello et al.(2005) pode-se comparar a produtividade de várias empresas que desenvolvem atividades parecidas e verificar as razões das disparidades, que geralmente estão relacionadas as decisões tomadas que melhor permitem aproveitar os recursos, devido ao uso de tecnologias mais avançadas, mão-de-obra mais qualificada, melhores técnicas gerenciais entre outros.

De acordo com estudos PUC-RIO (2014, p. 53) a Análise Envoltória de Dados (Data Envelopment Analisys - DEA) é :

Revista de Administração e Inovação, São Paulo, v. 12, n.4 p. 187-204, out./dez. 2015. 
Uma técnica de programação matemática que permite avaliar o grau de eficiência produtiva entre várias empresas, denominadas unidades tomadoras de decisão (DecisionMakingUnits - DMU's), considerando os recursos de que se dispõe (inputs) com os resultados alcançados (outputs).O princípio básico é medir e comparar o desempenho das unidades tomadoras de decisão, que realizam tarefas similares, considerando a relação entre insumos (inputs) e produtos (output).O DEA ainda facilita a identificação de organizações eficientes e não eficientes, através da análise comparativa do conjunto de inputs e outputs de cada DMU.

Pode-se ainda salientar que as organizações mais eficientes servem de benchmark, modelos de excelência.

Para Mello et al.(2005) a eficiência de uma DMU é a razão entre a sua produtividade e a produtividade da DMU mais eficiente, o resultado tem que ser uma eficiência, isto é, um número entre 0 e 1 , como podemos verificar abaixo:

$$
\begin{aligned}
& \text { Maximizar } \frac{u Y_{O}}{v X_{o}} \\
& \text { sujeito a } \\
& \frac{u Y_{k}}{v X_{k}} \leq 1 \text {, para todo } k
\end{aligned}
$$

Onde $\mathrm{X}$ são os inputs; $\mathrm{Y}$ os outputs; $\mathrm{K}$ refere-se ao total de Dmu's; v e usam vetores relacionados ao produto e aos insumos respectivamente, sendo variáveis de decisão.

Ainda segundo os autores há duas formas básicas de tornar uma unidade não eficiente em eficiente, podendo ser com orientação a inputs onde é reduzido os recursos, mantendo constantes os produtos, ou com orientação a outputs, pois mantém-se constantes os recursos visando o aumento do produto. Como pode ser observado na Figura 01:

\section{Figura 01 - Fronteira de Eficiência}

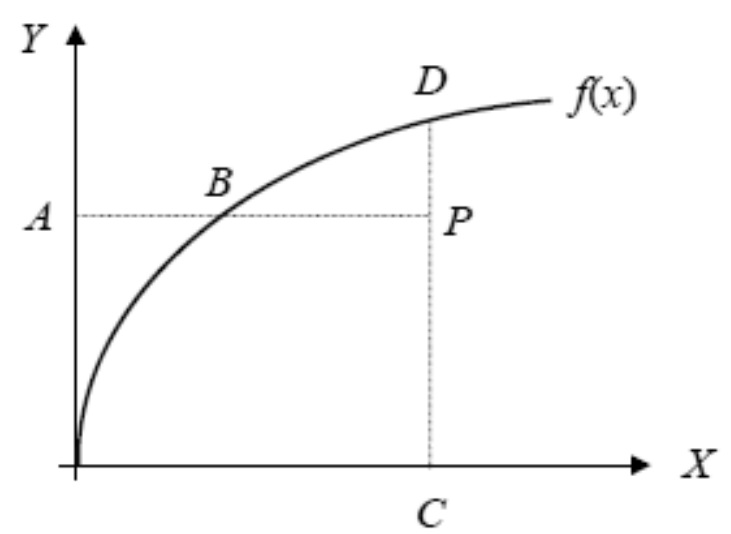

Revista de Administração e Inovação, São Paulo, v. 12, n.4 p. 187-204, out./dez. 2015. 
Onde:

Y: Produto

$\mathrm{X}$ : Insumos

$f(x)$ : Fronteira de eficiência

$\mathrm{O}$ ponto $P$ é ineficiente, para tornar-se eficiente pode-se reduzir recursos mantendo constante o produto, direcionando-se ao ponto $B$, a eficiência é definida pelo quociente $\mathrm{AB} / \mathrm{AP}$ e é um número entre 0 e 1. Caso preferir aumentar o produto mantendo constante os insumos deve-se dirigir até o ponto $D$, a eficiência é dada por CP/CD que também é um valor entre 0 e 1 .

Para realizar as análises, pode-se optar emutilizar, segundo Anjos (2005) métodos relacionados aos retornos de produção relativos às mudanças na escala de produção, que serão abordados a seguir.

\subsection{Modelo CCRe o modelo BCC}

Conforme Mello et al. (2005), o modelo CCR (Charnes, Cooper e Rhodes - 1978)utiliza retornos constantes de escala, onde variações nos inputs produz variações proporcionais nos outputs.

Para PUC-RIO (2014) este modelo também é conhecido como CRS (Constant Returnsto Scale) e define-se a eficiência como sendo a razão entre a soma ponderada dos produtos (output) e a soma ponderada dos insumos(inputs):

Para Anjos (2005) o modelo BBC (Banker, Charnes e Cooper - 1984) descreve a situação onde a variação do montante de insumos provoca uma variação (aumento ou diminuição) da produção mais do que proporcional. Essa diferença das duas óticas relaciona-se aos componentes da eficiência produtiva onde no modelo CCR utiliza-se para calcular o indicador de eficiência de escala e o modelo BCC a eficiência técnica.

Conforme PUC-RIO (2014) cita Belloni (2000), pode-se classificar os conceitos de eficiência da seguinte maneira:

- Eficiência produtiva: refere-se à habilidade de evitar desperdícios produzindo tantos resultados quanto os recursos utilizados permitem ou utilizando o mínimo de recursos possível para aquela produção. Tradicionalmente, a eficiência produtiva é decomposta em dois componentes: a eficiência de escala e a eficiência técnica.

Revista de Administração e Inovação, São Paulo, v. 12, n.4 p. 187-204, out./dez. 2015. 
- Eficiência de escala: é o componente da eficiência produtiva associado às variações de produtividade decorrentes de mudanças na escala de operação.

- Eficiência técnica: é o componente da eficiência produtiva que resulta quando são isolados os efeitos da eficiência de escala. A ineficiência técnica está associada à habilidade gerencial dos administradores.

\section{RESULTADOS E DISCUSSÕES}

Realizaram-se as análises de projeções com orientação output e retornos variáveis de escala, entre as atividades componentes do setor de indústria de transformação (DMU'S) no Estado do Paraná para os anos de 2000, 2003, 2005, 2008 e 2011, buscando medir a eficiência de cada atividade ao comparar o que foi produzido, dado os recursos disponíveis, com o que poderia ter sido produzido com os mesmos recursos.

É importante enfatizar que essa metodologia é uma medida de eficiência relativa, ou seja, os setores são considerados eficientes ou ineficientes dentro daqueles setores que estão sendo comparados.

\subsection{Análise para o ano 2000}

Verifica-se na Tabela 1, que o setor de fabricação de máquinas e equipamentos apresentou 99,25\% de eficiência, enquanto os setores de produtos alimentícios, fabricação de papel, embalagens e artefatos de papel e fabricação de produtos químicos apresentaram uma melhor alocação dos inputs (empresa que inovaram produtos e processos, empresas com mudanças estratégicas e organizacionais e dispêndios realizados em atividade inovativas) no sentido de maximizar o output (receitas líquidas). Se comparada com as atividades eficientes, o setor de máquinas e equipamentos poderia obter uma receita líquida final 0,75\% maior utilizando a mesma quantidade de inputs.

Tabela 1 - Níveis de eficiência das atividades das indústrias extrativas e de transformação no Paraná, 2000

\begin{tabular}{lc}
\hline Fabricação de produtos alimentícios & 1 \\
Fabricação de papel. embalagens e artefatos de papel & 1 \\
Fabricação de produtos químicos & 1 \\
Fabricação de máquinas e equipamentos & 0.9925 \\
\hline
\end{tabular}

Fonte: Resultados da Pesquisa

Revista de Administração e Inovação, São Paulo, v. 12, n.4 p. 187-204, out./dez. 2015. 
Em conformidade com os dados encontrados na base Pintec, no ano 2000 o setor de máquinas e equipamentos apresentou dados de número de empresas que inovaram produtos ou processo (input 1) e número de empresas que inovaram com mudanças estratégicas e organizacionais (input 2) abaixo da média do conjunto de setores, no entanto no quesito dispêndio com atividades inovadoras (input 3) apresentou o maior volume, e no comparativo de receita líquida (output 1) ficou atrás apenas do setor alimentício.

\subsection{Análise para o ano 2003}

Já em 2003, o setor de fabricação de máquinas e equipamentos passou a apresentar apenas 63,26\% de eficiência, conforme Tabela 2. E de acordo com os resultados obtidos, ao ser comparada com os setores de produtos alimentícios e de produtos químicos, a atividade poderia aumentar sua receita líquida em até 58,08\% utilizando a mesma quantidade de inputs já implantados.

\section{Tabela 2 - Níveis de eficiência das atividades das indústrias extrativas e de transformação no Paraná, 2003

\begin{tabular}{lc}
\hline Fabricação de papel. embalagens e artefatos de papel & 1 \\
Fabricação de produtos químicos & 1 \\
Fabricação de produtos alimentícios & 1 \\
Fabricação de máquinas e equipamentos & 0.6326 \\
\hline
\end{tabular}

Fonte: Resultados da Pesquisa

O setor de fabricação de máquinas e equipamentos apresenta dados de inovação na média das demais atividades. Considerando o input 3, dispêndios com atividades inovadoras, observa-se que o setor fica atrás apenas da fabricação de produtos alimentícios e já em relação a receita líquida mantémse abaixo da média.

\subsection{Análise para o ano 2005}

Para 2005, conforme Tabela 3, encontrou-se um número maior de atividades com dados disponíveis na base de dados, possibilitando uma comparação maior entre os níveis de eficiência. $\mathrm{O}$ setor de couros apresentou apenas $16,15 \%$ de eficiência na alocação de seus inputs se comparado com as atividades destaques material eletrônico e produtos químicos, poderia apresentar um desempenho melhor. As atividades relacionadas a produtos alimentícios, minerais não metálicos, peças e acessórios para veículos e produtos de madeira também tiveram notoriedade na alocação de seus inputs e geração de output.

Revista de Administração e Inovação, São Paulo, v. 12, n.4 p. 187-204, out./dez. 2015. 
A atividade de confecção de artigos do vestuário também apresentou baixa eficiência, apenas 23,08\% se comparado a alocação dos inputs da atividade de produtos de madeira e de minerais não metálicos.

\section{Tabela 3 - Níveis de eficiência das atividades das indústrias extrativas e de transformação no Paraná, 2005}

\begin{tabular}{lc}
\hline Fabricação de produtos alimentícios & 1 \\
Fabricação de produtos químicos & 1 \\
Fabricação de produtos de minerais não-metálicos & 1 \\
Fabricação de material eletrônico básico & 1 \\
Fabricação de peças e acessórios para veículos & 1 \\
Fabricação de produtos de madeira & 1 \\
Fabricação de produtos de metal & 0.8309 \\
Fabricação de máquinas e equipamentos & 0.7256 \\
Fabricação de artigos de borracha e plástico & 0.5292 \\
Fabricação de máquinas, aparelhos e materiais elétricos & 0.5131 \\
Fabricação de equipamentos de instrumentação médico-hosp. & 0.4641 \\
Fabricação de artigos do mobiliário & 0.3995 \\
Edição, impressão e reprodução de gravações & 0.3657 \\
Fabricação de produtos têxteis & 0.321 \\
Confecção de artigos do vestuário e acessórios & 0.2308 \\
Preparação de couros e fabricação de artefatos de couro & 0.1615 \\
\hline
\end{tabular}

Fonte: Resultados da Pesquisa

Verificou-se que os dados referentes ao setor de produtos alimentícios, modelo de excelência na alocação dos recursos, estão acima da média verificada entre os setores, já a fabricação de produtos de madeira apresentou dispêndio com atividades inovadoras abaixo da média observada, no entanto grande parte de suas representantes inovaram ou no produto e nos processos ou nas estratégias organizacionais.

Quanto à fabricação de produtos químicos, assim como o setor de peças e acessórios para veículos, não apresentaram números expressivos na inovação de produtos, processos e estratégias no período, mas destacaram-se nos quesitos dispêndios com atividades inovadorase receitas líquidas. Já os setores de materiais não metálicos e de materiais eletrônicos ficaram abaixo da média em todos os quesitos, no entanto alocaram seus recursos de forma eficiente.

Mesmo entre os setores menos eficientes, a atividade preparação e fabricação de artefatos de couros mostrou destaque no quesito dispêndio com atividades inovadoras, enquanto o setor de confecção de artigos do vestuário e acessórios apresentou valores acima da média no número de empresas que inovaram produtos, processos e estratégias organizacionais, no entanto mantiveram baixo tanto o dispêndio com atividades inovativas quanto as receitas líquidas, talvez por ser um setor onde os investimentos ocorrem em menor proporção se comparado a setores que demandem maiores montantes em suas pesquisas e no desenvolvimento de produtos.

Revista de Administração e Inovação, São Paulo, v. 12, n.4 p. 187-204, out./dez. 2015. 


\subsection{Análise para o ano 2008}

A Tabela 4 apresenta os resultados de 2008, verifica-se a baixa eficiência da fabricação de componentes eletrônicos, apenas 25,52\% de eficiência, se comparada aos setores eficientes como o de produtos siderúrgicos e de automóveis, caminhonetas e utilitários caminhões e ônibus. As atividades de produtos alimentícios e fabricação de cabines,carrocerias, reboques e recondicionamento de motores tambémsão referência para as outras atividades, na alocação dos inputs e maximização do output.

\section{Tabela 4 - Níveis de eficiência das atividades das indústrias extrativas e de transformação no} Paraná, 2008

\begin{tabular}{lc}
\hline Produtos siderúrgicos & 1 \\
Fabricação de automóveis, camionetas e utilitários, caminhões e ônibus & 1 \\
Fabricação de produtos alimentícios & 1 \\
Fabricação de cabines, carrocerias, reboques & 1 \\
Manutenção, reparação e instalação de máquinas e equipamentos & 0.869 \\
Fabricação de peças e acessórios para veículos & 0.8247 \\
Fabricação de produtos químicos & 0.6787 \\
Fabricação de máquinas e equipamentos & 0.6306 \\
Fabricação de artigos de borracha e plástico & 0.6192 \\
Confecção de artigos do vestuário e acessórios & 0.5169 \\
Fabricação de produtos de madeira & 0.4133 \\
Fabricação de produtos diversos & 0.3802 \\
Fabricação de produtos de minerais não metálicos & 0.3419 \\
Fabricação de componentes eletrônicos & 0.2552 \\
\hline
\end{tabular}

Fonte: Resultados da Pesquisa

Ao observar os dados referentes aos setores de fabricação de componentes eletrônicos que tanto o número de empresas que inovaram em produtos, processos e estratégias organizacionais. Também os dispêndios com atividades inovadoras e a receita líquida ficaram abaixo da média verificada para os setores, já a atividade de fabricação de produtos de minerais não metálicos destacou-se no quesito inovação de produtos ou processos.

\subsection{Análise para o ano 2011}

Para o ano de 2011, novamente há menos atividades com dados disponíveis na base da Pintec, apenas quatro setores apresentaram empresas que inovaram nas duas formas aqui apresentadas. 
Visualiza-se na Tabela 5, os benchmarks, os modelos de excelência, as DMU's representantes das atividades de fabricação de automóveis, caminhonetes e utilitários, ônibus e caminhões, fabricação de produtos alimentícios e refino de petróleo. Já a atividade de papel e embalagens apresentou maior ineficiência dentre os setores analisados, apenas $42,56 \%$.

\section{Tabela 5 - Níveis de eficiência das atividades das indústrias extrativas e de transformação no} Paraná, 2011

\begin{tabular}{lc}
\hline Fabricação de automóveis, caminhonetas e utilitários, caminhões e ônibus & 1 \\
Fabricação de produtos alimentícios & 1 \\
Refino de petróleo & 1 \\
Fabricação de papel. embalagens e artefatos de papel & 0.4256 \\
\hline
\end{tabular}

Fonte: Resultados da Pesquisa

A atividade de fabricação de papel, embalagens e artefatos de papel, apresentou valores abaixo da média para todos os quesitos analisados.

De início esperava-se que atividades com maior número de empresas que inovaram pudessem apresentar maiores valores também para lucro, como foi apresentado por Reis (2004), destacando a importância da inovação tecnológica para o aumento da rentabilidade da empresa inovadora. Saunila et al. (2014) também verificaram um efeito positivo e significativo dos determinantes da capacidade de inovação sobre a rentabilidade, e Heij et al. (2013), argumentam que atividades com níveis mais elevados de gestão da inovação mostram um melhor ajuste e um êxito muito maior no quesito inovação.

No entanto observou-se nesse estudo que mesmo atividades de menor expressão com menores números de empresas, atividades de bens de consumo não duráveis, que demandam inovações com graus não tão elevados de investimentos, gerando resultados menores de receitas líquidas também podem ser consideradas modelos de excelência na alocação de seus recursos.

Os resultados desse estudo corroboram de certa forma com Lorenzoni e Treter (2011), ao enaltecer o potencial de empresas e atividades de menor porte no sentido de, por meio do planejamento, organização e inovação também terem a oportunidade de tornarem-se rentáveis. Também verificam-se semelhanças nos achados de Ansari et al. (2010), onde verificam que dependendo do contexto, as práticas de difusão e adoção de inovações gerenciais podem desencadear diferentes padrões de adaptação, e não geram resultados corporativos uniformes. 


\section{CONCLUSÕES}

O objetivo do trabalho foi verificar entre as atividades que implementaram inovações na indústria de transformação, quais são mais eficientes em relação ao seu retorno financeiro no Estado do Paraná. O método para identificar os setores mais eficientes foi a Análise Envoltória de Dados (DEA).

Assim, este trabalho contribuiu para demonstrar a importância da inovação para a melhor utilização dos recursos nos segmentos do setor da indústria de transformação objetivando um melhor desempenho e maior rentabilidade. O desafio está em inovar, aprimorando constantemente para melhor organizar e produzir de forma mais econômica e rentável, de acordo com os padrões de cada setor.

Os resultados também indicam que as atividades que mais inovam não possuem necessariamente o máximo de receita possível dados seus investimentos. No entanto, ao estimularem investimentos em atividades inovadoras, sejam elas de produto, processos ou estratégia organizacionais e de marketing tornam-se modelos de excelência, aproveitando ao máximo seus recursos afim de maximizar suas receitas, fortalecendo a ideia de que o planejamento e uma gestão adequada geram maior rentabilidade.

As principais limitações do estudo relacionam-se a despadronização na divulgação dos resultados observados em períodos distintos, dificultando uma visão sistêmica da evolução de todas as atividades. Também observa-se as diversas atividades que compõem o setor da indústria de transformação, algumas com produtos com valores agregados superiores podendo apresentar algum tipo de vantagem sobre as demais, considerando por exemplo, a variável receita líquida. Isso pode ocorrer devido a alguns setores exigirem investimentos mais altos em pesquisas para o aperfeiçoamento e desenvolvimento de produtos, e consequentemente agregarem maior valor aos produtos.

O próximo passo dessa pesquisa será analisar cada setor individualmente, e assim comparar com os resultados encontrados aqui. Também sugere-se realizar outros estudos comparando os setores de indústria de transformação entre os estados do Brasil, ou até mesmo entre as regiões dos estados.

Revista de Administração e Inovação, São Paulo, v. 12, n.4 p. 187-204, out./dez. 2015. 


\section{REFERÊNCIAS}

Andreassi, T. (2007). Gestão da inovação tecnológica. São Paulo; Thomson.

Anjos, M. A. (2005). Aplicação da análise envoltória de dados (dea) no estudo da eficiência econômica da indústria têxtil brasileira nos anos 90.239 f. Tese (Doutorado em Engenharia da Produção e Sistemas) - UFSC, Florianópolis. 2005.

Ansari, S. M., Fiss, P. C., \& Zajac, E. J. (2010). Made to fit: how practices vary as they diffuse. Academy of Management Review, p.67-92.

Barbieri, J. C., Alvares, A. C. T.(2004). Inovações nas organizações empresariais. In: Barbieri, J. C. (org.) Organizações inovadoras: estudos e casos brasileiros. 2. Ed. Rio de Janeiro: FGV.

Brum, A. J. (2000). Desenvolvimento Econômico Brasileiro. 21 a Ed, Petrópolis, Vozes.

Cano, W. (2012). A desindustrialização no Brasil. Economia e Sociedade, Campinas, v.21, número especial, p.831-851.

DEPECON - Departamento de Pesquisas e Estudos Econômicos. (2014). Panorama da indústria de transformação brasileira.Recuperado em27 agosto, 2014: http://www.fiesp.com.br/indices-pesquisase-publicacoes/panorama-da-industria-de-transformacao-brasileira/.

Dutra, D. J. S., Hatakeyam, K., Carvalho, H. G., \& Francisco, A. C. (2005). A busca do lucro do inovador através da gestão do conhecimento nas micro e pequenas empresas enquadradas no simples. UEPG Ci. Hum., Ci. Soc. Apl., Ling., Letras e Artes, Ponta Grossa, p. 93-100.

FMI - Fundo Monetário Internacional. (2014). Brazil and the IMF. Recuperado de: http://www.imf.org/external/country/BRA/index.htm.

Heij, C. V., Volberda, H. W., \& Van Den Bosch, F. A. J. (2013). How to leverage the impact of new technological on product and service innovations: The complementary effect of management innovation. Working paper. Rotterdam School of Management, Erasmus University, Rotterdam.

IBGE - Instituto Brasileiro de Geografia e Estatística. (2007). Classificação Nacional das Atividades Econômicas - $\quad$ CNAE 2.0. Recuperado de: http://www.ibge.gov.br/home/estatistica/economia/classificacoes/cnae2.0/cnae2.0.pdf 
IBGE - Instituto Brasileiro de Geografia e Estatística. (2011). Contas regionais do Brasil. Recuperado de:

http://www.ibge.gov.br/home/presidencia/noticias/imprensa/ppts/000000154227111920132729211259 25.pdf.

IBGE - Instituto Brasileiro de Geografia e Estatística. (2014). Contas nacionais trimestrais. Recuperado de: http://www.ibge.gov.br/home/estatistica/indicadores/pib/pib-vol-val_201402_8.shtm.

IPARDES - Instituto Paranaense de Desenvolvimento Econômico e Social. (2014). Paraná em números. Recuperado de: http://www.ipardes.gov.br/index.php?pg_conteudo=1\&cod_conteudo=1.

Mello, J. C. C. B. S., Meza, L. A., Gomes, E. G., \& Neto, L. B. (2005). Curso de análise envoltória de dados. XXXVII Simpósio brasileiro de pesquisa operacional. Recuperado de: http://www.uff.br/decisao/sbpo2005_curso.pdf.

OCDE. (2005) Manual de Oslo - Diretrizes para coleta e interpretação de dados sobre inovação. $3^{\mathrm{a}}$ ed. FINEP.

PIA - Pesquisa Industrial Anual (2011). Pesquisa Industrial. Recuperado de: http://www.ibge.gov.br/home/estatistica/economia/industria/pia/empresas/2011/defaultempresa.shtm.

PINTEC - Pesquisa de Inovação Tecnológica. (2014). Pesquisa de inovação - dados. Recuperado de: http://www.pintec.ibge.gov.br/index.php?option=com_content_extjs\&view=article\&id=17\&Itemid=6.

PME - Pesquisa Mensal de Emprego. (2014). Pesquisa Mensal deEmprego.Recuperado em 02 setembro, 2014: http://www.ibge.gov.br/home/estatistica/indicadores/trabalhoerendimento/pme_nova/.

PUC-RIO. (2014). Análise envoltória de dados (DEA) e uma proposta de modelo para avaliar a eficiência das empresas de comércio eletrônico.Recuperado em23 julho, 2014: <http://www.maxwell.vrac.puc-rio.br/9973/9973_5.PDF.

Reis, D. (2004). Gestão da Inovação Tecnológica. $1^{\text {a }}$ ed. São Paulo: Ed. Manole.

Saunila, M., Ukko, J., \& Rantanen, H. (2014). Does Innovation Capability Really Matter for the Profitability of SMEs? Knowledge and Process Management, 21(2), p. 134-142, April/June.

Silva, A. O., \& Mendes, J. T. G. (2014). Economia e gestão. São Paulo: Pearson. 
Volberda, H. W., Van Den Bosch, F. A. J., \& Heij, C. V. (2013). Management Innovation: Management as Fertile Ground for Innovation.European Management Review, 50(1), p. 1-15.

\title{
EFFICIENCY OF INNOVATION PROCESSES FOR PROCESSING INDUSTRY: AN ANALYSIS IN THE STATE OF PARANÁ
}

\begin{abstract}
In 2011, the industry accounted for 27.28\% of GDP in the State of Paraná, representing in 2013, 5.84\% of Brazil's GDP, highlighting the segments of automotive vehicles, food and petroleum refining. However comes up watching in recent years, an industry decrease of participation in the economy, the process of de-industrialization, where it turns out that the challenges related to globalization and increased competitiveness are directly linked to innovation processes. The objective is to verify that the activities implemented innovations in the manufacturing industry are more efficient in relation to its financial return in the state of Paraná. The research is exploratory, which applies to linear programming technical data envelopment analysis (DEA - Data Envelopment Analysis) from the series of data collected for the years 2000, 2003, 2005, 2008 and 2011 we used the BCC model with orientation outputs, considering returns scale variables holding constant the resources and increasing output. In this scenario, it appears that the activities that will innovate not necessarily have the highest net revenues due to standard issue for each sector, related to higher investments in research and development of products with high added values, but even with a size less than or producing industrial goods with lower unit value, by stimulating innovative activities, become benchmarks, making the most of its resources in order to maximize their revenue, making profitable and competitive industry.
\end{abstract}

Keywords: Efiência; Industry; Innovation.

Data do recebimento do artigo: 06/08/2015

Data do aceite de publicação: 09/12/2015

Revista de Administração e Inovação, São Paulo, v. 12, n.4 p. 187-204, out./dez. 2015. 